\title{
Bleeding together: Caitlin Hackett and companion ecologies
}

\section{Michael Uhall}

Abstract: this short article introduces the concept of companion ecologies, then explores more fully how that concept intersects with and relies upon the underlying infrastructure of aesthetic experience. Principally, it focuses on how artworks by the independent artist Caitlin Hackett evidence how the concept in question takes shape by means of its encounter with the aesthetic. More generally, the article serves to illustrate the degree to which our theoretical imagination relies upon affective and aesthetic dimensions that often go disavowed or displaced, a point also made by thinkers like Michèle Le Doeuff and Jean-Luc Nancy.

Let's start with a concept, then see what makes that concept come alive. By the end, we will have learned something important about how the ecological and the imaginary inform each other, both aesthetically and theoretically.

The term "companion ecologies" refers our attention to the material contexts and temporal scales in which subjectivity emerges. ${ }^{[1]}$ Animal subjects, human or otherwise, individuate and take shape precisely because of the ecological plurality underlying them, because of the companion ecologies that constitute them. Consequently, companion ecologies refer to the conditions of possibility for subject formation, but the term also functions as a distinct referent in its own right.

An ecology as such is a composite, multimodal, yet entitative plurality.

What does this mean? An ecology is composite because, unlike a mere aggregate, the various parts of an ecology are layered irreducibly upon each other, like trophic levels, each depending on all of the others. An ecology is multimodal, because the parts in question do not belong necessarily to the same physical modes and ontological orders, any more than do organisms and more discontiguous elements, like soils, water cycles, and weathers. An ecology is also entitative insofar as we can refer to it as a determinate identity or milieu. In other words, ecologies bleed together - ironically, in both senses of that phrase: to bleed together, which is to say, both to suffer in conjunction and to overlap, even to such a degree that the demarcations between identities start to break down. But we nevertheless can distinguish between different ecologies, say, at different scales, or in different sites. Finally, an ecology is a plurality because its parts both appear and exercise themselves as distinct, albeit radically interdependent, entities.

The artist Caitlin Hackett's work in visual media - principally, in the form of illustrations and paintings - not only challenges and informs this concept of companion ecologies, but infuses the rather abstract concept with affective and associational dimensions that are difficult if not impossible to capture by means of the theoretical 
imagination alone. Accordingly, my intention in what follows is not to show off how a set of visual images simply exemplifies a concept. That merely would reproduce a logic of subordination we should reject.

Rather, I want to direct our attention to the degree to which our concepts and theories necessarily rely upon an aesthetic infrastructure that typically ends up being disavowed. On the one hand, the philosopher Michèle Le Doeuff makes the point directly, arguing that the philosophical tradition always has relied upon mythical, rhetorical, or visual imagery while simultaneously derogating or minimizing the role of the image in thought. (Emblematically, one recalls Plato's exoteric hostility for myth and poetry, accompanied as it is by his esoteric reliance on core myths and Orphic, even occult imagery.) On the other hand, she writes: "the meaning conveyed by images works both for and against the system that deploys them. For, because they sustain something which the system cannot itself justify, but which is nevertheless needed for its proper working. Against, for the same reason - or almost: their meaning is incompatible with the system's possibilities." [2]

Starting from Le Doeuff's observation, I propose a closer examination of several artworks by Hackett.

These artworks, as well as the rest of her body of work, perform several functions. Principally, the latent agency or vitality of the images generates and sustains an aesthetic infrastructure that prevents the concept of companion ecologies I propose from slipping into mere nomenclatural innovation. Indeed, Hackett animates the concept at a distance. You could say the work of art here breathes life into thought. It is akin to a kind of necromancy - or, rather, the opposite of necromancy, a kind of biomancy.

In brief: Hackett's work produces companion ecologies, and her production of this concept -which is both avant la lettre and sui generis - exceeds any theoretical description of the concept as such. In performing companion ecologies, Hackett's work makes apparent the irreducible presence of the companionate (or what Jean-Luc Nancy calls "co-appearing" [com-parait], or "compearance" [com-parution]) and the dark remainder of subjectivity that haunts every ecology. ${ }^{[3]}$

First and foremost, then, let's see how Hackett's imagery produces - even performs - companion ecologies.

Consider Figure 1 ("Growth and Decay"), which depicts a squirrel contorted and traversed by generative forces. On closer examination, we see the anatomy of the squirrel deviates from what is typically expected from a squirrel. Six limbs grasp at the void, and the squirrel clutches at the skull of another of her type, like a bloody ghost held dear. The teratology depicted here is not the teratology of deformation, but, instead, of continual transformation beyond the limitations of the merely strange or uncanny. Positioned at the front is a metonymy of the squirrel's desire - an acorn, the seed of arboreal life. Tendrils of growth extending from out of the acorn enclose the squirrel, both embracing and strangling corporeal form. What is this life that grows out from another? Out of the squirrel's own body burst forth leaves, seeds, and stems, promising something like regrowth even as they visually threaten the squirrel's own bodily integrity and shape.

In Figure 2 ("Time Is Not on Our Side"), the intimate relationship between sites of mortality and sites of natality gets depicted and plumbed further, this time within the framework of the human itself. 


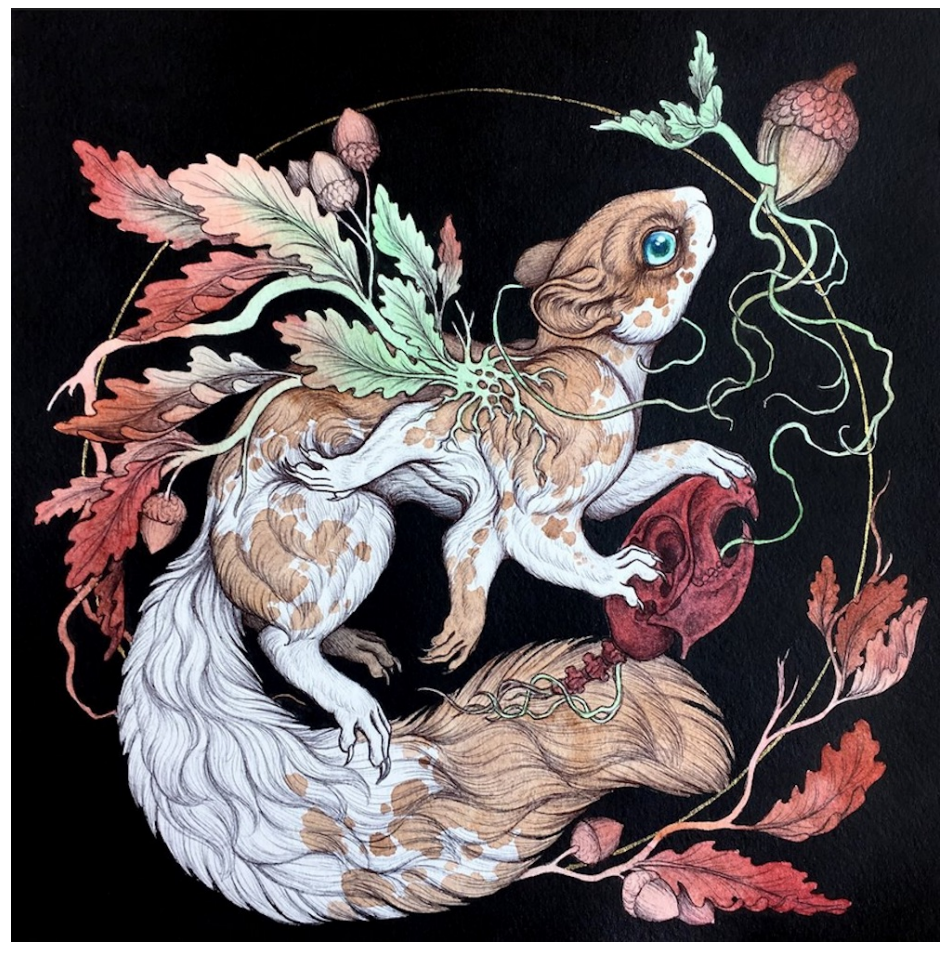

Figure 1. "Growth and Decay." Copyright Caitlin Hackett, 2017.

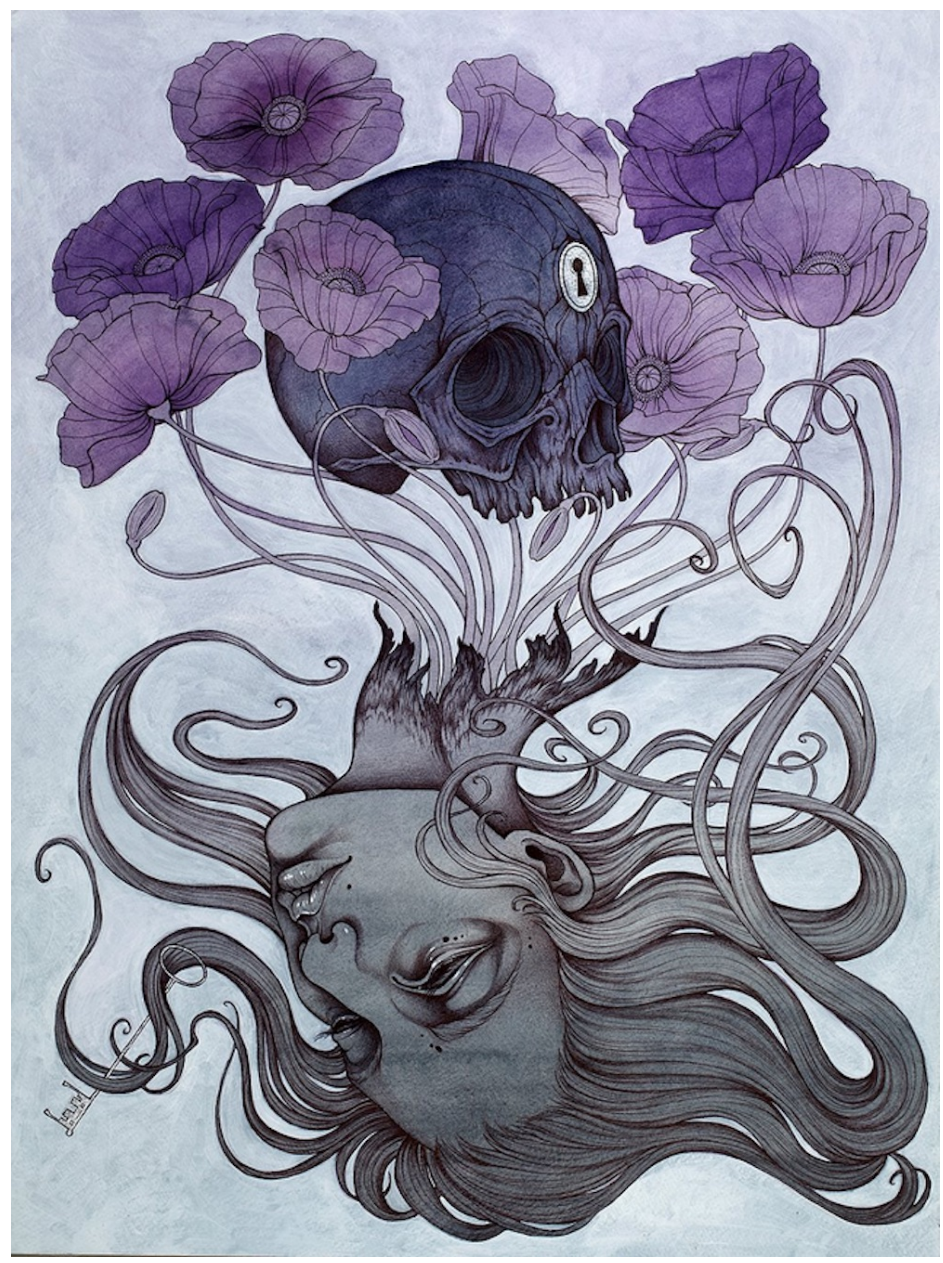

An ashen, disembodied head crumbles, or falls away, from a richly purple skull as if cast off like an old chrysalis. Surrounding the skull is a bed of dark anemones, the stems of which burst forth from the neck. Tentacular blossoms intertwine with flowing hair, introducing elements of visual confusion into this portrait of inversion. Key to the image is precisely a key, easily overlooked, as if lost in the tresses. Central to the skull is a lock protruding from its forehead. The image contains both a lock and the key to that lock: you could say the image unlocks itself.

These figures emphasize constitutive interconnectivity - that is to say, the interweaving of life and death, of the organic and the inorganic, of the human and the inhuman. They embody dynamic reciprocity, continually inverting the distinctions upon which we so often rely. In this regard, the work is fundamentally ecological in its nature. Hackett clearly portrays boundaries between entities - we can identify squirrels and skulls, blossoms and tendrils - but these boundaries exist precisely as amorphous contact zones and protean passageways.

It is like the images are feeling themselves up.

That which separates also brings together inexorably. As such, the images depict cleavings, as in "to cleave," meaning both "to adhere" or "to cling" and "to divide" or "to split apart." They are composites - amalgamations of growth and decay - and also multimodal, incorporating bodies, objects, temporalities, transitions.

How, then, does Hackett's work animate, rather than merely exemplify, the concept of companion ecologies? Answering this question should not close down interpretive avenues. Rather, it opens up an entirely new landscape of interpretive possibility and theoretical acuity. Rather than

Figure 2. "Time Is Not on Our Side." Copyright Caitlin Hackett, undated. 
viewing the images as exemplars or tokens, we can start to see how the images themselves provide publicly accessible sites of figural agency.

We could say, stressing the sheer weirdness of the following utterance: The images themselves are thinking. In this sense, my readings of Hackett's artworks are deeply informed by the strategies of "weird reading" suggested so fruitfully by Eileen Joy. ${ }^{[4]}$ Here we step away even from Hackett's own aims and intentions as an artist and into the speculative ecology of the image alone.

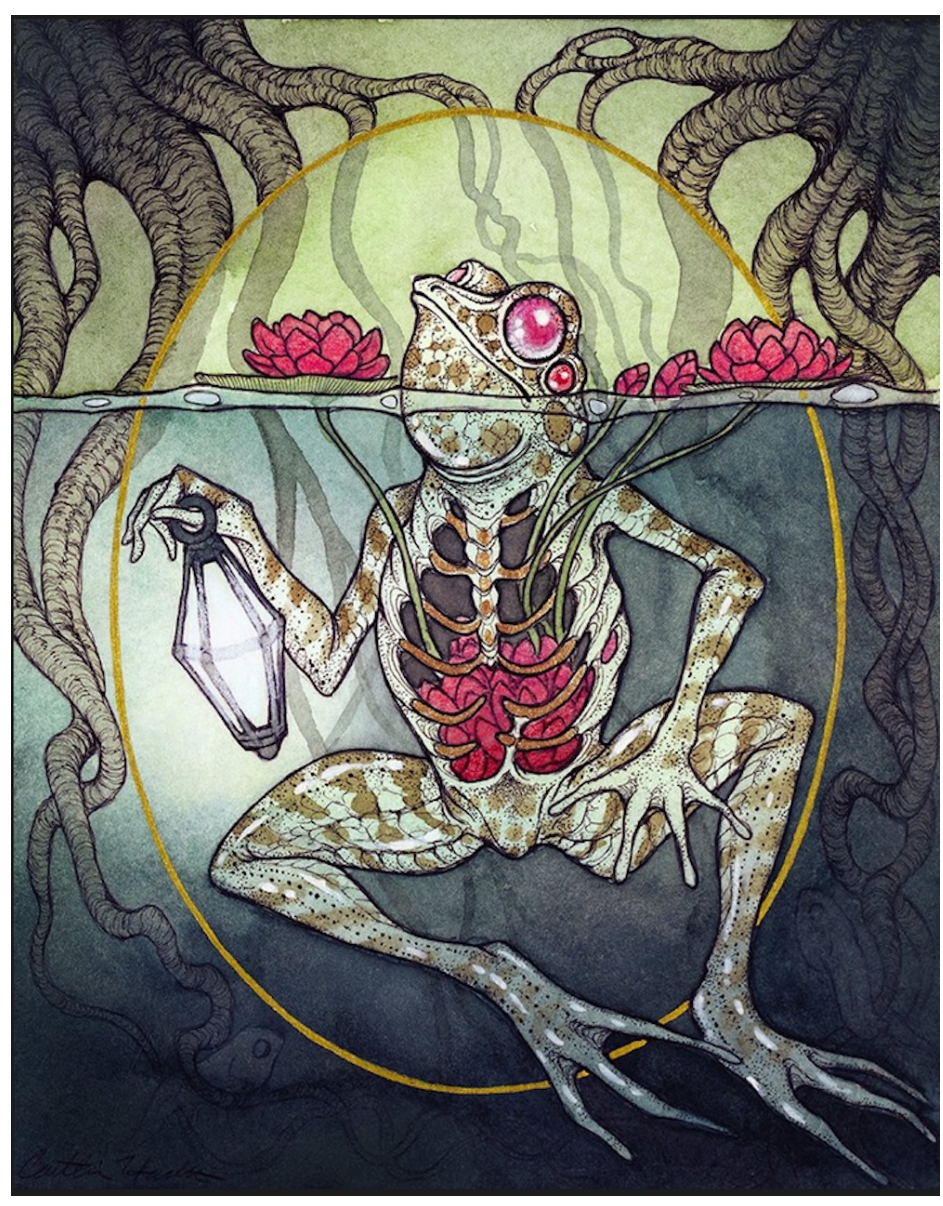

Figure 3. “The Guide.” Copyright Caitlin Hackett, 2015.

\author{
Consider Figures 3 ("The Guide") and 4 ("Ex \\ Fortuna").
}

Both images frame the central figure with a halo, evoking the sensibility of religious iconography. Perhaps these are portraits of the new martyrs of the ecological. Indeed, often Hackett's chimeras are pierced by arrows, like so many creaturely Saint Sebastians (see also Figure 5 ["Heavy Hearted"]).

Figure 3 depicts a partially skeletonized frog, whose stark viscera births the red lotuses attached to it by vegetal tendrils. The portrait is framed by even more tendrils, dark roots descending into darkness. The frog - who breaches the surface, serving as one point of intersection between Darwin's entangled bank and his warm little pond - bears a lantern, illuminating the gloom. Who is the guide supposed to be guiding? Is it us? Can this amphibian figure lead us into some strange new future? Is it the larva clustered around its feet? Or is this liminal creature guiding only itself?

In Figure 4, we see a hybrid rabbit perched in a threatening wasteland, surrounded by smoldering poppies. The rabbit bears distinctly human arms, inked with vines. From the slits of its ribcage, vegetal life again bursts forth, winding around the figure like an island of ambiguous fertility. Ironically, this animal saint - freshly "out of luck" clutches at a charm. Perhaps the foot of some fellow rabbit has become a token of its supplication.

As with Figures 1 and 2, a skull haunts the rabbit. In both of these images, one can hear the echo of the Polish writer Bruno Schulz, whispering, "lifelessness is only a disguise behind which hide unknown forms of life."[5]

The coupling depicted in Figure 6 ("I Was Made for You") emblematically evokes the teratological dynamics that so frequently inform and traverse Hackett's work. These hounds are conjoined at the face, and their conjunction serves as the site of emergence for an unexpected eye. Strange vision receives articulation from a strange vision. From the mouths of the hounds, crimson branches or vines erupt, barks giving voice to bark and cherry blossoms, which, in turn, attract luminous moths fluttering in the void. One of the moths exits a cocoon, its muted 


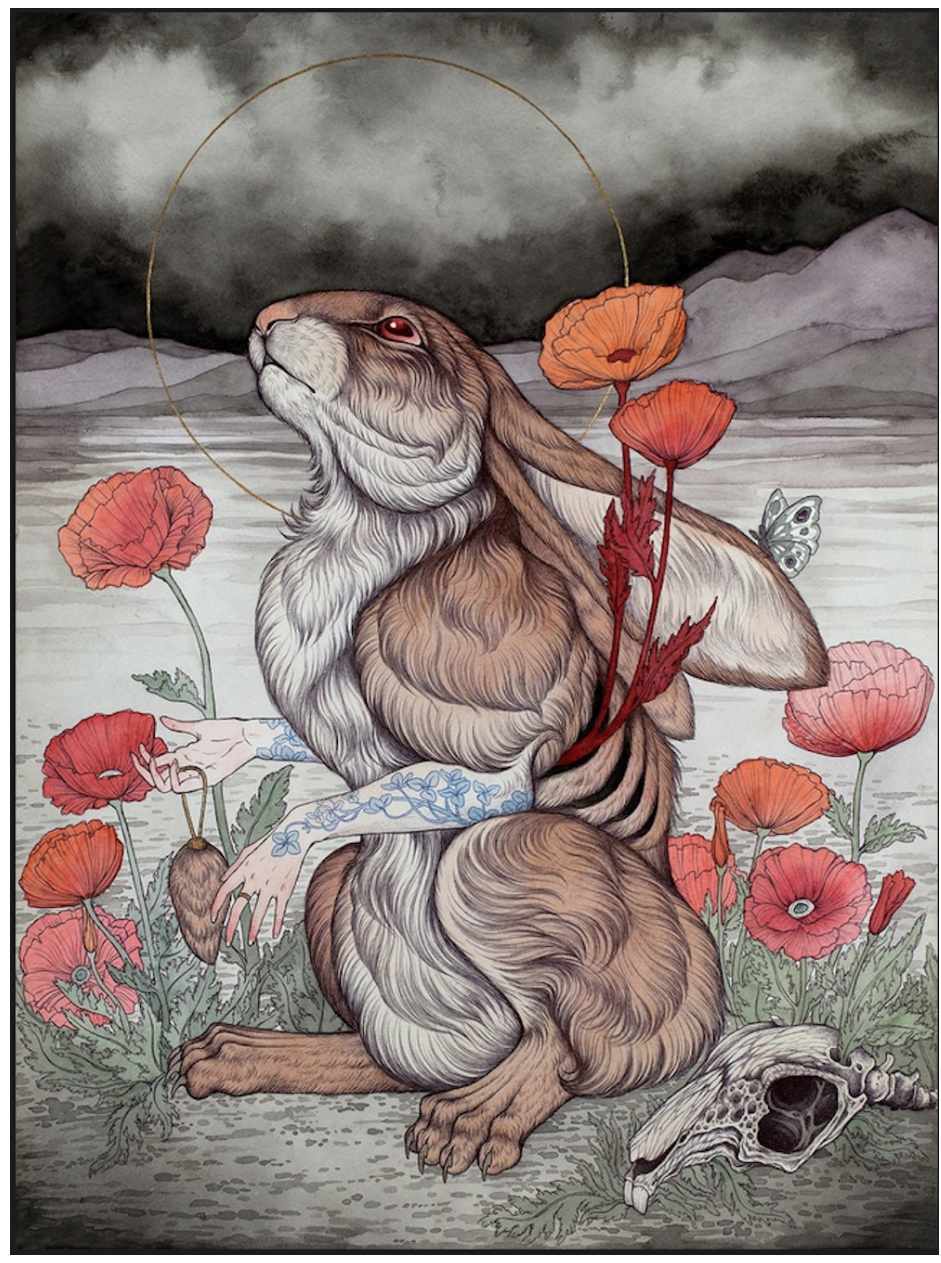

Figure 4. "Ex Fortuna." Copyright Caitlin Hackett, undated. purple tones echoing the hounds' gray fur. What does the image think? The companionate is inescapable, irreducible. To coin a verb: Life companionates. We see creatures entangled and intertwined, in states of transition that bind together even as they individuate themselves. The unexpected eye implies a novel form of sight, directing our attention toward how viewing the ecological in companionate terms changes what we are able to see in the very first place. Something monstrous haunts the image, as with all these images. Hackett's creatures - her companion ecologies - they are monstrous, yet monstrously beautiful. They emerge like biological specters from out the night of creative darkness that engenders them. They are contrastive figures, also. Fertile figments, metamorphic forms, tortured bodies. Each one guides, laments, speaks, and supplicates, gesturing toward the ecological conditions of the real we irrevocably share as company together during the many brief sojourns of organismic life.

In Figure 7 ("The Last Masquerade"), the image returns us to the seat - indeed, the site - of subjectivity itself. The dark remainder becomes a

flock of masks, as red threads bind animal faces to the raptorine body itself. The owl plays host to blossoms, vines, the grinning skull at the heart of the world, yet it is no memento mori. The owl's form functions like a visual hierophant, clutching with human hands at a branch of the tree of life as the world darkens before a storm. The tree bears keys like strange fruit, keys for the locks each mask carries upon its feathered brow.

The subject is a play of ecological forces - perfectly real, perfectly interdependent, perfectly individuated - and thereby tied to animal forms, to companion ecologies, to material mysteries that exceed anything like a mere concept of the subject itself. As the scientists Gregory W. Schneider and Russell Winslow remark, "individuality in organisms emerges, paradoxically, as a consequence of plurality."[6]

Hackett's work collides with the ecological, and it simultaneously animates and explodes the concept of companion ecologies with which I began. In these images, there is a dialectic between the mode of speculative mapping performed by the theoretical imagination and the degree to which all such mappings operate only on the basis of an aesthetic infrastructure that exceeds, informs, and fractures the act of thinking altogether. The artwork itself is one form that a companion ecology can take, performing new intersections between modes of the real that, somehow, both accompany and precede all acts of intellection.

\section{References}




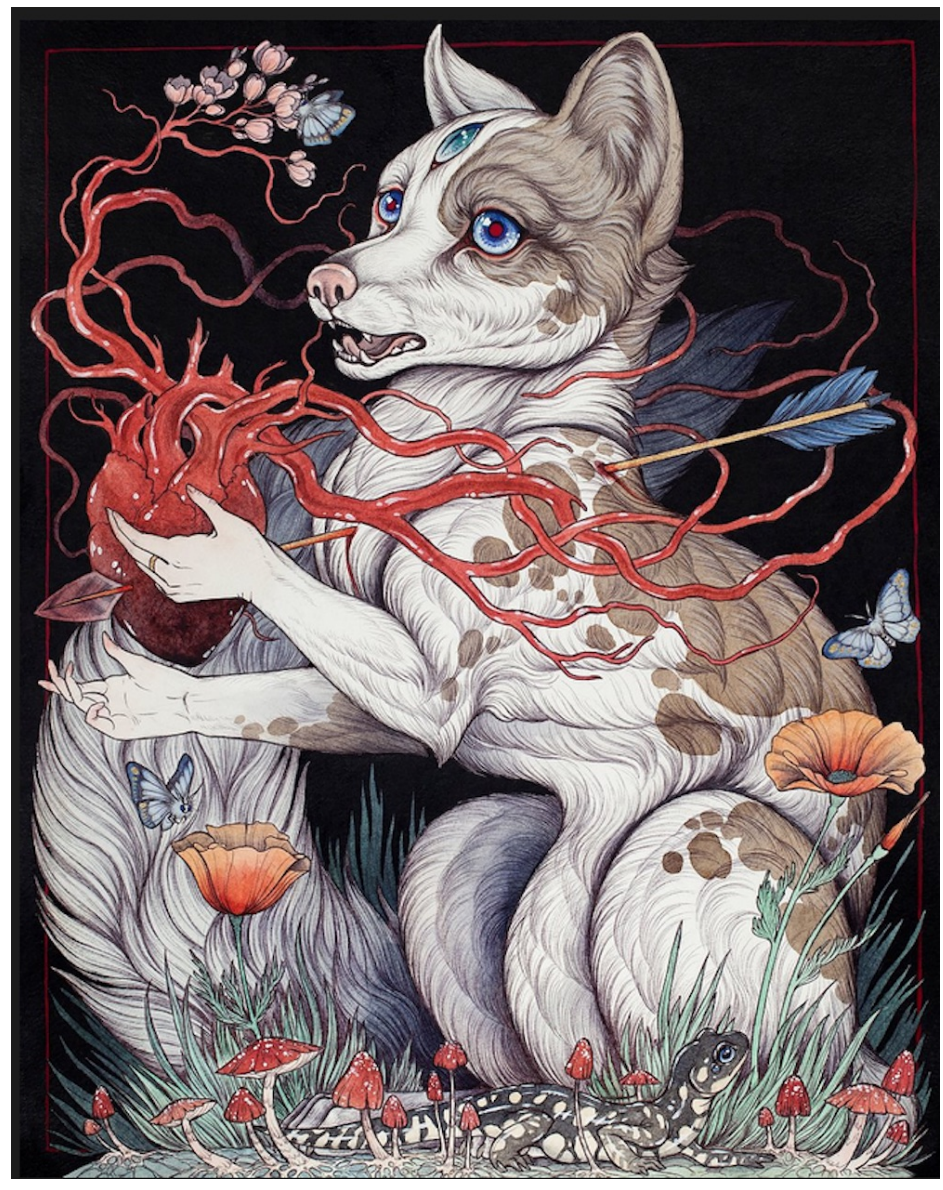

Figure 5. "Heavy Hearted." Copyright Caitlin Hackett, undated.

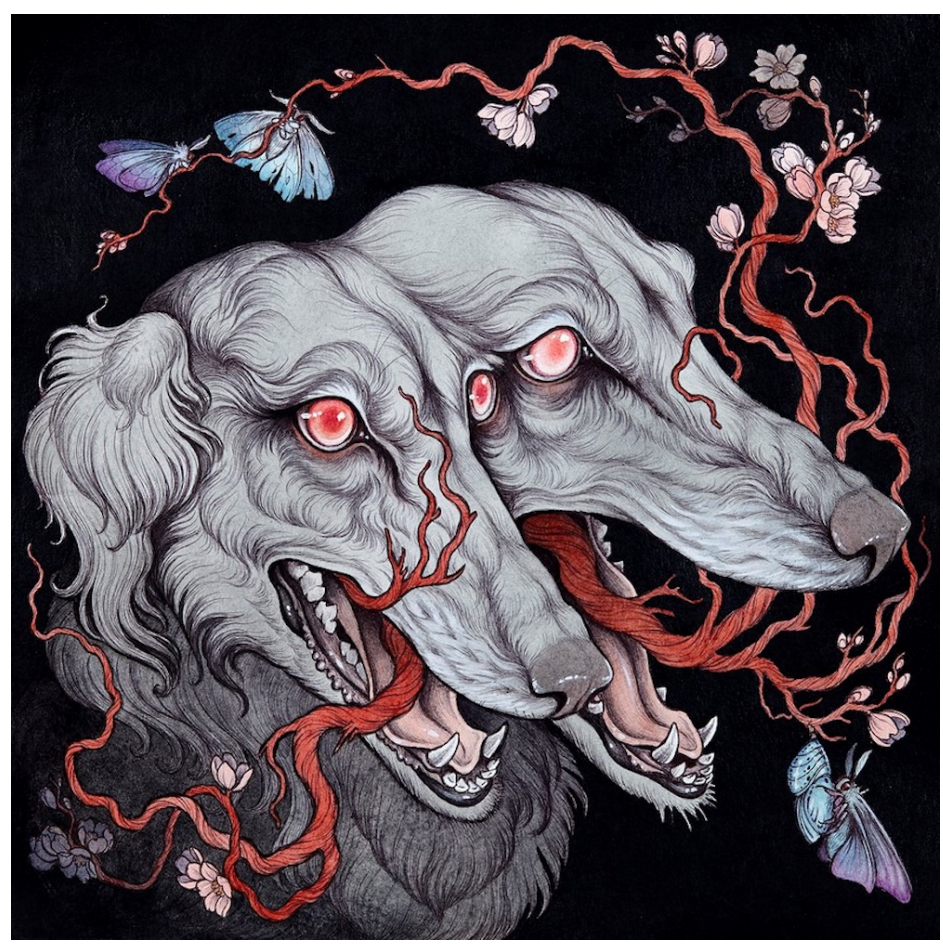

Figure 6. "I Was Made for You." Copyright Caitlin Hackett, 2017.
Hackett, Caitlin. http://www.caitlinhackett.com/.

Joy, Eileen. "Weird Reading." Speculations IV: $A$ Journal of Speculative Realism (2013): 28-34.

Le Doeuff, Michèle. 2002. The Philosophical Imaginary. Translated by Colin Gordon. London and New York: Continuum.

Nancy, Jean-Luc. 1991. The Inoperative Community. Translated by Peter Connor. Minneapolis: University of Minnesota Press.

Schneider, Gregory W. and Russell Winslow. "Parts and Wholes: The Human Microbiome, Ecological Ontology, and the Challenges of Community." Perspectives in Biology and Medicine 57:2 (2014): 208-23.

Schulz, Bruno. 1977. The Street of Crocodiles. Translated by Celina Wieniewska. New York: Penguin Books.

\section{Notes}

1. Michael Uhall, "Companion ecologies: a new theory of the subject," Contemporary Political Theory (forthcoming).

2. Michèle Le Doeuff, The Philosophical Imaginary, trans. Colin Gordon (London and New York: Continuum, 2002), 3, emphases in original.

3. Jean-Luc Nancy, Being Singular Plural, trans. Anne O'Byrne (Stanford: Stanford University Press, 2000), 56-59.

4. Eileen Joy, "Weird Reading," Speculations IV: A Journal of Speculative Realism (2013): 28-34.

5. Bruno Schulz, The Street of Crocodiles, trans. Celina Wieniewska (New York: Penguin Books, 1977), 59-60.

6. Gregory W. Schneider and Russell Winslow, "Parts and Wholes: The Human Microbiome, Ecological Ontology, and the Challenges of Community," Perspectives in Biology and Medicine 57:2 (2014): 208 , emphasis in original. 


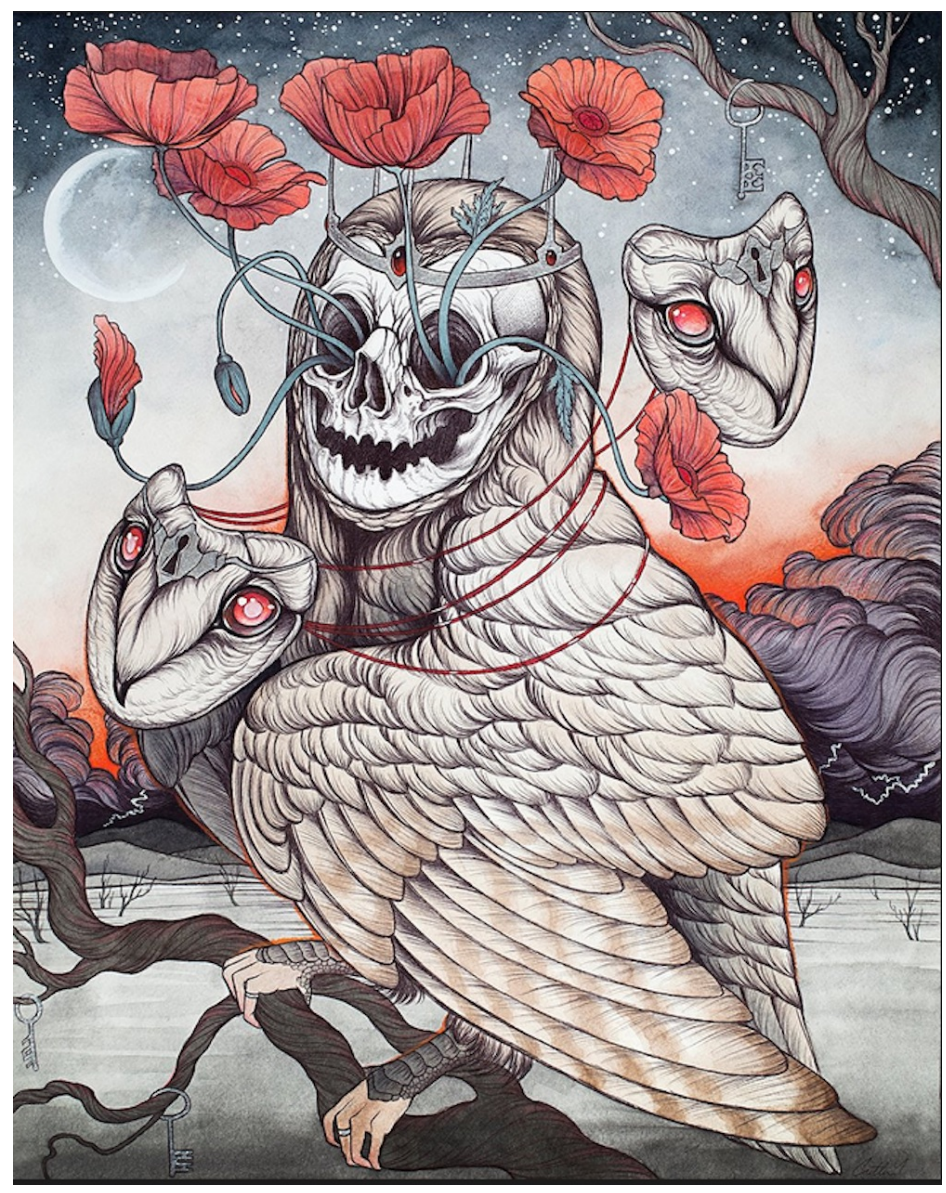

\section{Cite this Essay}

Uhall, Michael. "Bleeding together: Caitlin Hackett and companion ecologies." Rhizomes: Cultural Studies in Emerging Knowledge, no. 37, 2021, doi:10.20415/rhiz/037.e07

Figure 7. "The Last Masquerade." Copyright Caitlin Hackett, undated.

RHIZOMES ISSN 1555-9998 ^ 230 East Hall Bowling Green State University Bowling Green, OH 43403

Editors: Ellen Berry and Carol Siegel. Reviews editor: Craig J. Saper. Technical editor: Helen J Burgess 